\title{
Superelevation Calculation of Debris Flow Climbing Ascending Slopes
}

\author{
HaiXin Zhao, ${ }^{1,2}$ Yong You, ${ }^{2,3}$ JinFeng Liu, ${ }^{2,3}$ and LingKan Yao \\ ${ }^{1}$ School of Civil Engineering, Southwest Jiaotong University, Chengdu, Sichuan 610031, China \\ ${ }^{2}$ Key Laboratory of Mountain Surface Process and Hazards, CAS, Chengdu 610041, China \\ ${ }^{3}$ Institute of Mountain Hazards and Environment, CAS, Chengdu 610041, China
}

Correspondence should be addressed to Yong You; yyong@imde.ac.cn

Received 28 November 2016; Revised 18 February 2017; Accepted 12 March 2017; Published 30 March 2017

Academic Editor: Sandro Longo

Copyright (C) 2017 HaiXin Zhao et al. This is an open access article distributed under the Creative Commons Attribution License, which permits unrestricted use, distribution, and reproduction in any medium, provided the original work is properly cited.

\begin{abstract}
We present a new method for calculating the superelevation of debris flow when it encounters obstacles in the process of flowing. Our calculation method is based on the Bingham Model for debris flow determination and considers the vertical difference of debris flow velocity and characteristic parameters of debris flow on a hypothetical basis. Moreover, we conducted an indoor flume experiment to verify the accuracy and reasonability of our calculation method. The experimental results showed that our method is able to accurately calculate the superelevation of debris flow with a root-mean-square error (16\%). Furthermore, we provide an in-depth example of how our calculation method can be employed. Ultimately, we conclusively prove that our calculation method can be used for the superelevation calculation of debris flow climbing ascending slopes. Finally, we provide more exact parameters for debris flow protection engineering.
\end{abstract}

\section{Introduction}

Debris flow causes superelevation when it encounters obstacles in the flow process, or when channels suddenly become narrow. This is the result of the kinetic energy of the debris flow being converted to potential energy in the space of a single instant [1]. Extremely high superelevation of debris flow can be disastrous and cause casualties, in part because people do not pay sufficient attention to the risks posed by debris flow [2]. For instance, debris flow in Qiongshan Gully in the upper Dadu River basin climbed a slope of more than 15 meters and smashed a building, killing 51 people in 2003 [3].

The accurate calculation of maximum superelevation of debris flow is crucial for designing debris flow prevention projects $[1,4,5]$. For example, when designing debris dams, builders must factor in how debris flow will impact the dam, such as the occurrence of superelevation on the wing wall. Superelevation on the wing wall is disadvantageous to the stability of the dam body because the debris flow could potentially bypass the wing wall and flush out on the sides of the dam, causing corrosion between the back of the dam and nearby gullies. Thus, the accurate calculation of maximum superelevation is paramount.

Additionally, design parameter calculations for drainage canals and protection embankments also require the exact calculation of debris flow superelevation in terms of debris flow encountering obstacles. If the calculation of superelevation is too low, the debris flow can bypass protection engineering projects and damage farmlands, villages, towns, and roads.

Previous studies have proposed calculation methods that use the mean velocity of debris flow and the law of conservation of energy for determining the maximum superelevation of debris flow climbing ascending slopes [1]. These superelevation results were typically used to back-calculate the debris flow velocity of large-scale flume experiments [69]. Mancarella and Hungr [10] used a dynamic model based on shallow-flow assumptions to study debris flow predictions for rapid landslides and avalanches against protective dikes and walls placed perpendicular to the path of the debris flow. Choic et al. [11] used flume experiments and the 


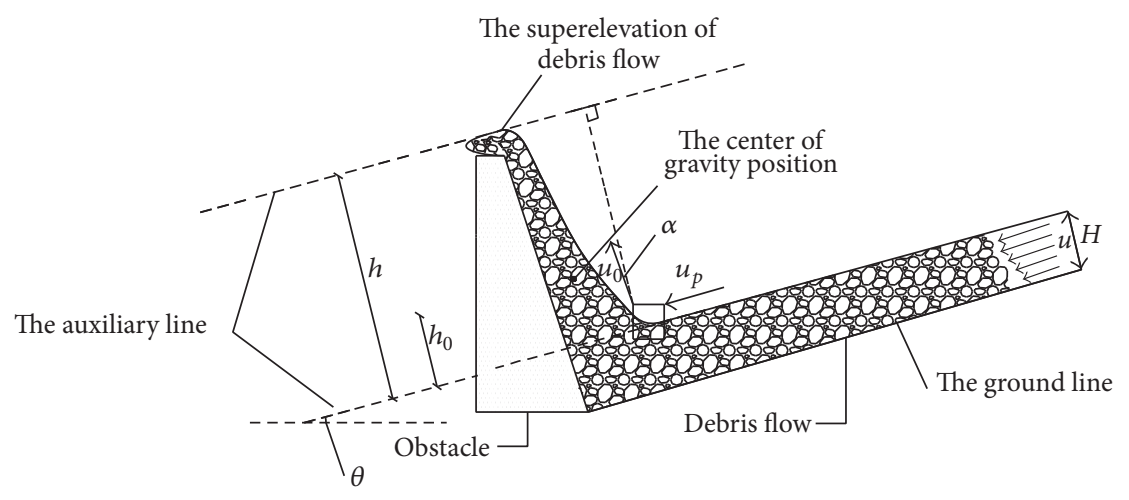

FIGURE 1: A schematic layout of the superelevation of debris flow.

discrete element method (DEM) to study the interaction between debris flow and the baffles, a kind of structural countermeasure positioned along the flow path, which can change flow depth and cause superelevation. Iverson et al. [12] have argued that debris flow run-up is influenced by both smooth momentum fluxes and abrupt momentum jumps and that heights vary systematically with slope angle, effective basal friction, and the flow Froude number. To be successful, run-up predictions must account for the unsteadiness of incoming flows.

On one hand, the results of the above calculation methods have been flawed and inaccurate. For instance, calculations based on the mean velocity of debris flow had large errors, which implies that there are implicit dangers in current prevention and control engineering methods. On the other hand, alternative and potentially more accurate calculation methods are too complex to be applied in practical engineering. As such, we propose a new method to calculate the superelevation of debris flow climbing ascending slopes. The accuracy and applicability of our method were verified by the results of 9 indoor flume experiments. We conclude by providing more exact parameters for debris flow protection engineering.

\section{Theoretical Equation Based on the Bingham Model}

We assume that the debris flow impinging on an obstacle is 2dimensional (2D), based on Bingham Model and unaffected by the dynamics of run-up on the obstacle.

By comparing the differences between measured data and calculated data [1], we found that most superelevation calculations for debris flow were smaller than the measured value. The main reasons for this occurrence are as follows:

(1) The former calculation methods were deduced by energy methods:

$$
h=\frac{a \cdot v^{2}}{2 g},
$$

where $h$ is the superelevation of debris flow, $a$ is the function of the slope, $v$ is the mean velocity of the debris flow, and $g$ is the gravitational acceleration.

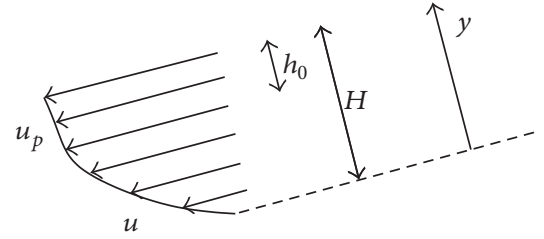

Figure 2: The Bingham Model.

Equation (1) regards debris flow as a moving whole which treats a debris flow as a highly idealized frictionless point mass and calculates the superelevation of debris flow climbing ascending slopes as the height of the debris flow center of gravity (as a whole, $h_{0}$ ), whereas the actual superelevation of debris flow climbing ascending slopes is the edge height of the mud depth from the surface of the debris flow $h, h_{0}<h$ (as shown in Figure 1).

(2) The velocity of the debris flow in (1) is the mean velocity, which is not uniformly distributed in the scope of the mud depth. In diluted debris flows, the surface velocity is larger than the mean velocity; in viscous debris flows, there is a "plug" in the vertical direction of the distribution in which the velocity is larger than the mean velocity of the debris flow [13-16].

Based on the above analysis, we selected a micro unit of the debris flow surface as the object of the energy balance. We used the Bingham Model to calculate the superelevation of the debris flow.

In the Bingham Model, it is understood that the velocity is not evenly distributed vertically; however, there is a uniform section of velocity that we refer to as "plug." "Plug" is the scope of $h_{0}$ in Figure 2. Below the "plug," the velocity of the debris flow decreases quickly and the bottom velocity is zero. The shear force $\tau$ in the Bingham Model is

$$
\tau=\tau_{B}+\eta \frac{\partial u}{\partial y}
$$

where $\eta$ is the coefficient of the viscosity and $\tau_{B}$ is Bingham limit shear stress.

The shear force is

$$
\tau=\gamma_{c}(H-y) J
$$


where $\gamma_{c}$ is the bulk density, $H$ is the mud depth, and $J$ is the slope of the gully. By combining (2) and (3), we were able to obtain the velocity below the "plug," based on vertical integration.

$$
u=\frac{y}{2 \eta}\left(2 \gamma_{c} J-\gamma_{c} J y-2 \tau_{B}\right)
$$

The thickness of the "plug" is

$$
h_{0}=\frac{\tau_{B}}{\gamma_{c} J} \text {. }
$$

The velocity at the top of the "nonplug" is equal to the velocity in the "plug" section, and the surface velocity is the velocity in the "plug" section.

$$
u_{p}=u_{\left(H-h_{0}\right)}=\frac{\gamma_{c} H^{2} J}{2 \eta}\left(1-\frac{\tau_{B}}{\gamma_{c} H J}\right)^{2} .
$$

Meanwhile, we were able to obtain the mean velocity in Bingham Model based on vertical integration.

$$
v=\frac{\gamma_{c} H^{2} J}{3 \eta}\left[1-\frac{3}{2} \frac{\tau_{B}}{\gamma_{c} H J}+\frac{1}{2}\left(\frac{\tau_{B}}{\gamma_{c} H J}\right)^{3}\right],
$$

where $v$ is the mean velocity.

In order to simplify the calculation, we operated under the following hypothesis: the bottom of the debris flow met and overflowed all obstacles, resulting in the formation of a smooth surface in the wake of the debris flow. As such, the surface velocity of the debris flow changed direction, but not value. Specifically, $u_{0}=u_{p}$ (Figure 1 ), and the direction of $u_{0}$ was parallel to the surface of the obstacle. Meanwhile, some forces are neglected: forces on mass boundary and internal friction causing dissipation and outflow kinetic energy.

The micro unit of the surface of the debris flow caused energy principle.

$$
\Delta m g \cos \theta \cdot h=\frac{1}{2} \Delta m\left(u_{p} \cos \alpha \sin \beta\right)^{2},
$$

where $\alpha$ is the angle between $u_{0}$ and the vertical of $u_{p}$ (Figure 1), specifically the angle between the vertical of the direction of debris flow and the surface of the obstacle on the plane parallel to the direction of debris flow but perpendicular to the horizontal plane (Figure 3). $\beta$ is the angle between the direction of the debris flow and the surface of the obstacle on the plane parallel to the ground and $\theta$ is the channel slope (Figure 3), which was small in the field and had $\cos \theta \approx 1$, meaning this item could be omitted.

Note. Auxiliary line $l$ is parallel to $u_{p}, m$ is parallel to $u_{0}, p$ is the intersecting line between the ground and the surface of obstacle, $n$ is perpendicular to $l$, the plane composed by $n$ and $l$ is perpendicular to the horizontal plane, $q$ is parallel to horizontal plane, $\alpha$ is the angle between $m$ and $n, \beta$ is the angle between $l$ and $p$, and $\theta$ is the angle between $q$ and the ground.

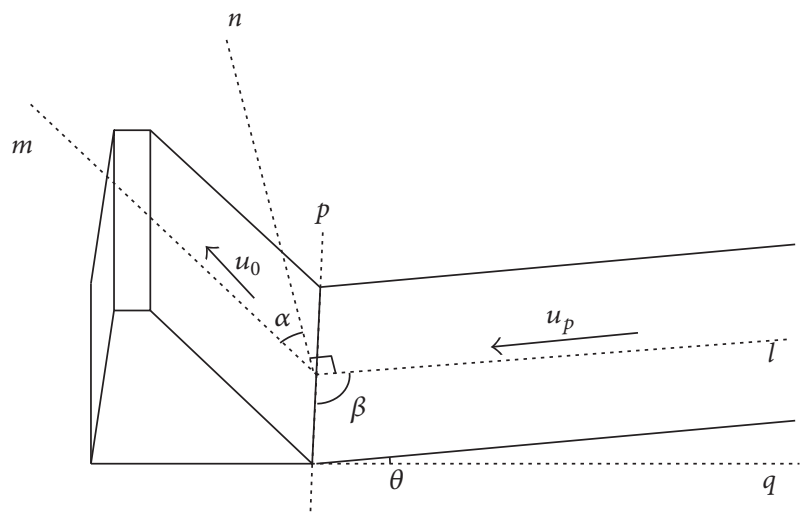

FIGURE 3: A 3D sketch of velocities and angles about debris flow.

Finally, we obtained the theoretical superelevation of debris flow climbing ascending slopes based on the Bingham Model.

$$
h=\frac{\gamma_{c}^{2} H^{4} J^{2} \cos ^{2} \alpha \sin ^{2} \beta}{8 \eta^{2} g}\left(1-\frac{\tau_{B}}{\gamma_{c} H J}\right)^{4} .
$$

The newly deduced equation (9) utilizes a micro unit from the surface of debris flow to serve as the object of study. Equation (9) (based on the Bingham Model) considers characteristics such as density, grain composition, coefficients of viscosity, and gradients of slopes, which makes its calculations highly accurate.

\section{Verification and Analysis of Equations}

3.1. Specifications for the Experimental Model. In this study, we conducted our experiments in a debris flow simulation laboratory at the Institute of Mountain Hazards and Environment, part of the Chinese Academy of Sciences (CAS). The experimental facility consisted of a hopper, flume, obstacle model, and tailings pool. Figure 4 shows a schematic illustration of the experimental model. The hopper was rectangular with a length of $60 \mathrm{~cm}$, a width of $60 \mathrm{~cm}$, and a height of $80 \mathrm{~cm}$. It had the capacity of $0.1 \mathrm{~m}^{3}$, and it was affixed to the flume and controlled the discharge from the gate. We conducted our experiments in a flume with a length of $400 \mathrm{~cm}$, a width of $30 \mathrm{~cm}$, and a height of $40 \mathrm{~cm}$. The gradient of the flume was adjustable from $0^{\circ}$ to $20^{\circ}$. We placed a model of an obstacle at the bottom of the flume. The modelled obstacle had a surface slope of $63^{\circ}$. We used the tailings pool to recycle the debris flow.

3.2. Experimental Materials. We collected experimental material samples for use in our indoor flume experiments from sites located in Gan Gully, the Level 1 tributary canal of the Yinchang Gully in the upper stream of the Qian River in the Longmen mountain town of Pengzhou, Sichuan Province. At this location, there was an outbreak of large-scale debris flow on the night of August 18, 2012. The specific sampling sites were located on the east side of the alluvial fan. The maximum particle size of the experimental materials was 
TABLE 1: Experimental conditions and combinations for debris flow scouring experiments on different flume slopes with different debris flow bulk densities.

\begin{tabular}{lccc}
\hline Density $\left(\mathrm{g} / \mathrm{cm}^{3}\right)$ & Volume $(\mathrm{L})$ & Flume slope $\left(^{\circ}\right)$ & Surface slope of obstacle $\left(^{\circ}\right)$ \\
\hline $19,20,21$ & 60 & $7,11,15$ & 63
\end{tabular}

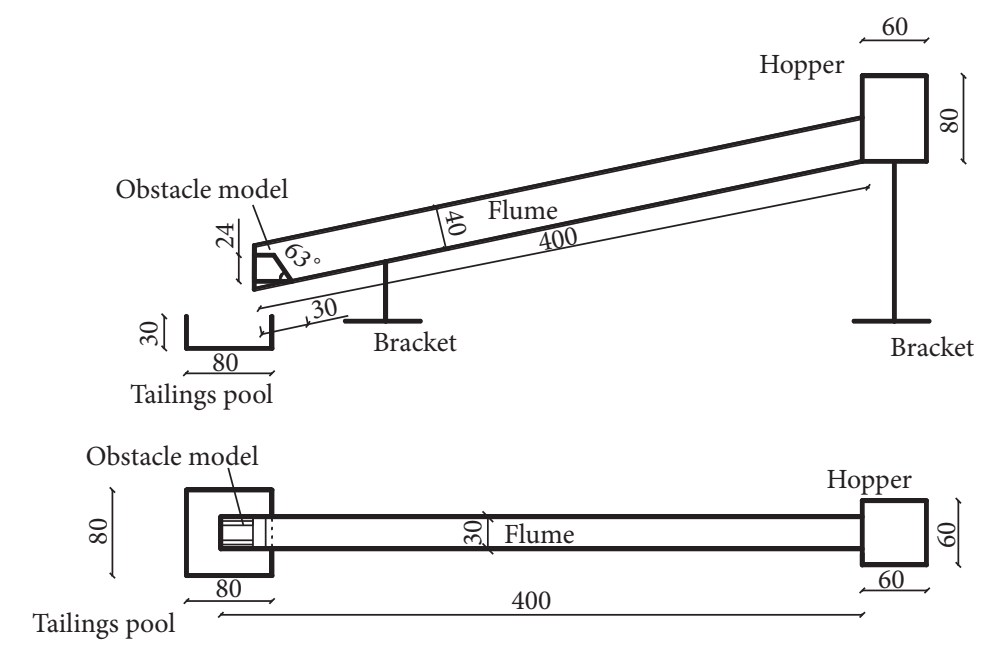

FIGURE 4: A schematic diagram of the experimental apparatus $(\mathrm{cm})$.

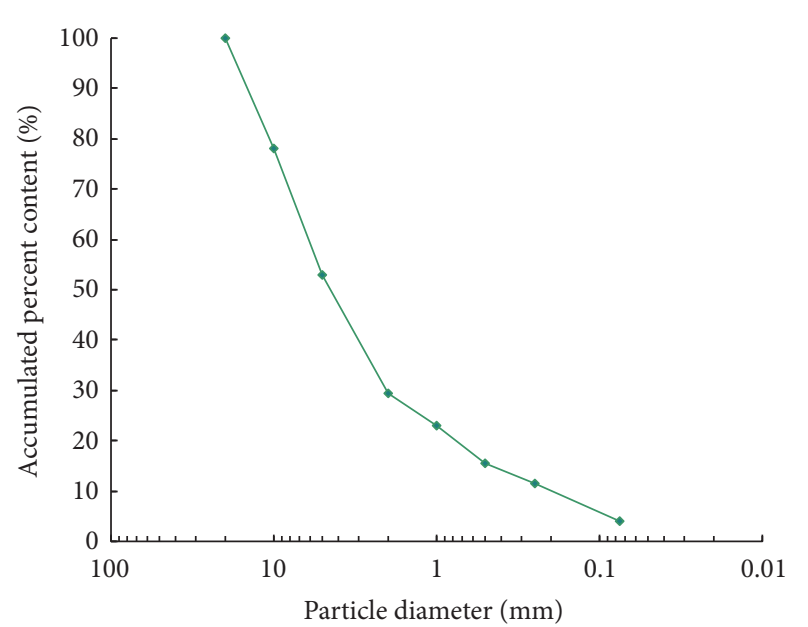

Figure 5: Particle gradation of the materials used in the experiment.

$20 \mathrm{~mm}$. We took 5 random samples for grain size distribution analysis before conducting the experiments. Figure 5 shows the grain size distribution of the experimental materials.

3.3. The Experimental Contents and Phenomenon. For the experiment, we installed a ruler on one side of the flume. We then used a high-speed camera to record the mean velocity of the debris flow and the superelevation climbing ascending slopes. We calculated the mean velocity of the debris flow by measuring the length of time it took for the head of the debris flow to move a specified distance. We determined the superelevation climbing the ascending slopes by measuring the highest position of the debris flow. We used the subsequent calculations and measurements for our analysis (Table 1).

We found that the progress of the debris flow could be divided into 3 stages (Figure 6): (1) the acceleration stage, (2) the uniform stage, and (3) the decelerating stage. When we opened the gate of the hopper, the speed of the debris flow gradually increased with gravity, as shown in Figure 6(a). The debris flow reached a uniform state as a result of frictional resistance from the bottom, sides, and insides of the material. When the debris flow encountered obstacles, the obstacles and the two inside lateral surfaces of the flume formed a closed constraint space in the direction of the debris flow, which generated a superelevation of debris flow as (b)-(d). With a loss of energy, the last of the debris flow could not climb over the obstacles, causing the debris flow to "swing back" or reverse. This reversal caused a buildup of silt in the reservoir, making (e)-(f) and becoming static in the end.

\section{Comparison of Calculated and Experimental Results}

4.1. The Preparation of the Rheological Parameters. We began by obtaining some parameters of the debris flow using rheological tests. We created a debris flow with a density of $19 \mathrm{kN} / \mathrm{m}^{3}, 20 \mathrm{kN} / \mathrm{m}^{3}$, and $21 \mathrm{kN} / \mathrm{m}^{3}$. We then filtered out particles with a diameter larger than $1 \mathrm{~mm}$ by using a circular screen. After filtering, we used water to clean the circular screen so that finer particles would not be filtered. We then soaked the samples for 24 hours before conducting the rheological test. Table 2 provides the results of the rheological properties of the viscous debris flow $[17,18]$. 


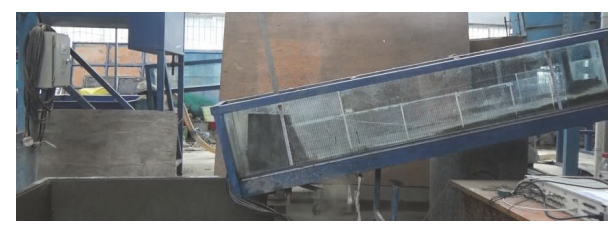

(a)

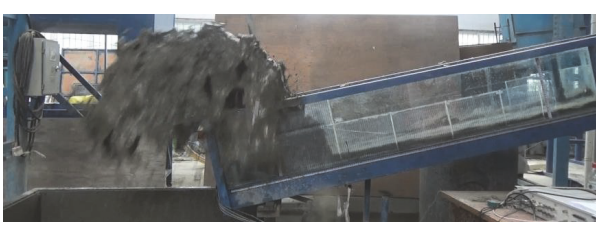

(c)

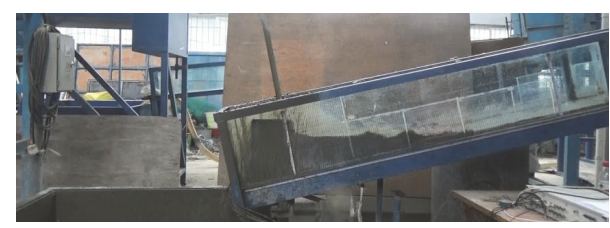

(e)

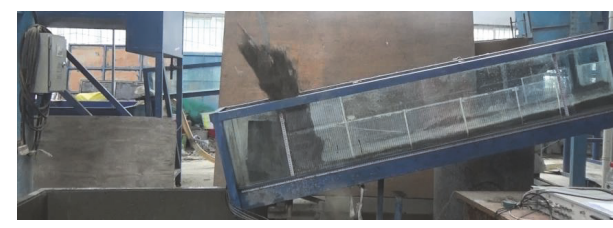

(b)

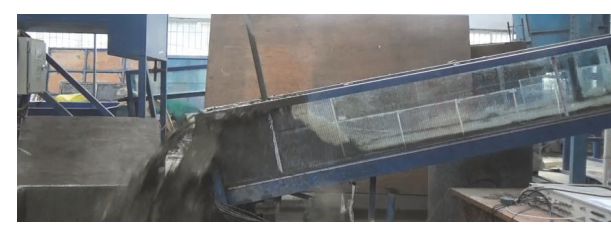

(d)

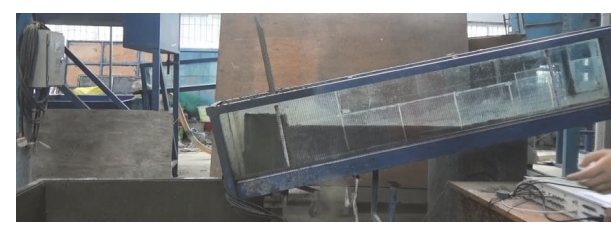

(f)

Figure 6: The phenomenon of the superelevation of debris flow climbing ascending slopes. (a), (b), (c), (d), (e), and (f) are time series photos of debris flow accelerating (a), the phenomenon of superelevation (b), maximum superelevation (c), superelevation fall down (d), the swinging back of silt (e), and the back silting remaining static (f).

TABLE 2: Analysis of the rheological properties of the debris flow.

\begin{tabular}{lcr}
\hline Density $\left(\mathrm{kN} / \mathrm{m}^{3}\right)$ & Coefficient of viscosity $\eta(\mathrm{Pa} \cdot \mathrm{s})$ & Bingham limit shear stress $\tau_{B}(\mathrm{~Pa})$ \\
\hline 19.00 & 0.49 & 2.10 \\
20.00 & 0.62 & 4.90 \\
21.00 & 1.00 & 15.00 \\
\hline
\end{tabular}

4.2. The Results of the Experiment. After preparing the rheological parameters, we calculated the superelevation climbing ascending slope using the rheological properties parameters of the debris flow, the measured lead mean velocity, and the measured superelevation using (1) and a modified version of (9). Table 3 shows the comparison results.

Note. $R$ means hydraulic radius, which is calculated by

$$
R=\frac{W \cdot H}{2 H+W}
$$

where $W$ is the width of the flume and $W=30 \mathrm{~cm}$. In the indoor experiments we conducted, the hydraulic radius differed from the mud depth, which we used to accurately calculate the results. $v_{1}$ represents the true mean velocity measured by determining the time it took for the debris flow head to pass through a fixed distance. $v_{2}$ represents the surface velocity of the debris flow calculated by (6) in which we used the hydraulic radius $R$ instead of the mud depth $H$ due to a theoretical derivation based on the Bingham Model. The derivation is based on a 2-dimensional (2D) model and is better suited for calculations using the hydraulic radius $R$ instead of the mud depth $H$ in the experiments when considering the effects of the two inside lateral surfaces of the flume. $v_{3}$ represents the value of mean velocity calculated by (7). We compared the true mean velocity $v_{1}$ and the calculated mean velocity by (7) and showed their correlations in Figure 7 . We could verify that the flow parameters, apparent viscosity, and yield stress are consistent with stream depth $H$ and mean measured velocity $v_{1}$.

In Table $3, h_{0}$ represents the true superelevation measured by reading the high definition image. $h_{1}$ represents the calculated superelevation measured by the mean velocity $v_{1} . h_{2}$ represents the calculated superelevation calculated by surface velocity $v_{2}$ using $R$ instead of $H$ in (9). Specifically, it uses

$$
h=\frac{\gamma_{c}^{2} R^{4} J^{2} \cos ^{2} \alpha \sin ^{2} \beta}{8 \eta^{2} g}\left(1-\frac{\tau_{B}}{\gamma_{c} R J}\right)^{4},
$$

where $\varepsilon_{1}$ is the relative error between the true superelevation $h_{0}$ and the calculated superelevation $h_{1}$ measured by the mean velocity $v_{1}$ and $\varepsilon_{2}$ is the relative error between the true superelevation $h_{0}$ and the calculated superelevation $h_{2}$ determined by using

$$
\varepsilon_{1,2}=\frac{h_{1,2}-h_{0}}{h_{0}} \times 100 \% .
$$

After analyzing the results shown in Table 3, we compared the true superelevation $h_{0}$ and the calculated superelevation $h_{2}$ (Figure 8), as well as their correlations (Figure 9). 
TABLE 3: The calculated values of the superelevation $h_{1}$ and superelevation $h_{2}$ and the results of the flume experiments $h_{0}$.

\begin{tabular}{lccccccccccccccc}
\hline Number & $\begin{array}{c}\gamma_{c} \\
\left(\mathrm{kN} / \mathrm{m}^{3}\right)\end{array}$ & $J$ & $\begin{array}{c}H \\
(\mathrm{~cm})\end{array}$ & $\begin{array}{c}\eta \\
(\mathrm{Pa} \cdot \mathrm{s})\end{array}$ & $\begin{array}{c}\tau_{B} \\
(\mathrm{~Pa})\end{array}$ & $\begin{array}{c}R \\
(\mathrm{~cm})\end{array}$ & $\begin{array}{c}v_{1} \\
(\mathrm{~m} / \mathrm{s})\end{array}$ & $\begin{array}{c}v_{2} \\
(\mathrm{~m} / \mathrm{s})\end{array}$ & $\begin{array}{c}v_{3} \\
(\mathrm{~m} / \mathrm{s})\end{array}$ & $\begin{array}{c}h_{0} \\
(\mathrm{~mm})\end{array}$ & $\begin{array}{c}h_{1} \\
(\mathrm{~mm})\end{array}$ & $\begin{array}{c}h_{2} \\
(\mathrm{~mm})\end{array}$ & $\begin{array}{c}\varepsilon_{1} \\
\varepsilon_{2}\end{array}$ \\
\hline 1 & 21 & 0.12 & 5.6 & 1.00 & 15.0 & 4.08 & 1.16 & 1.53 & 1.09 & 90.2 & 68.65 & 105.21 & $-24 \%$ & $17 \%$ \\
2 & 21 & 0.19 & 5.0 & 1.00 & 15.0 & 3.75 & 1.71 & 2.27 & 1.59 & 198.0 & 149.19 & 238.06 & $-25 \%$ & $20 \%$ \\
3 & 21 & 0.27 & 4.5 & 1.00 & 15.0 & 3.46 & 2.17 & 2.89 & 2.00 & 403.0 & 240.25 & 395.09 & $-40 \%$ & $-2 \%$ \\
4 & 20 & 0.12 & 4.5 & 0.62 & 6.9 & 3.46 & 1.52 & 1.95 & 1.35 & 140.7 & 117.88 & 171.32 & $-16 \%$ & $22 \%$ \\
5 & 20 & 0.19 & 3.9 & 0.62 & 6.9 & 3.10 & 1.80 & 2.61 & 1.79 & 264.6 & 165.31 & 312.38 & $-38 \%$ & $18 \%$ \\
6 & 20 & 0.27 & 3.6 & 0.62 & 6.9 & 2.90 & 2.28 & 3.35 & 2.28 & 511.4 & 265.22 & 530.57 & $-48 \%$ & $4 \%$ \\
7 & 19 & 0.12 & 4.5 & 0.49 & 2.1 & 3.46 & 1.71 & 2.64 & 1.78 & 400.2 & 149.19 & 314.35 & $-63 \%$ & $-21 \%$ \\
8 & 19 & 0.19 & 3.8 & 0.49 & 2.1 & 3.03 & 2.03 & 3.25 & 2.19 & 410.6 & 210.25 & 489.75 & $-49 \%$ & $19 \%$ \\
9 & 19 & 0.27 & 3.3 & 0.49 & 2.1 & 2.70 & 2.50 & 3.70 & 2.49 & 675.6 & 318.88 & 650.68 & $-53 \%$ & $-4 \%$ \\
\hline
\end{tabular}

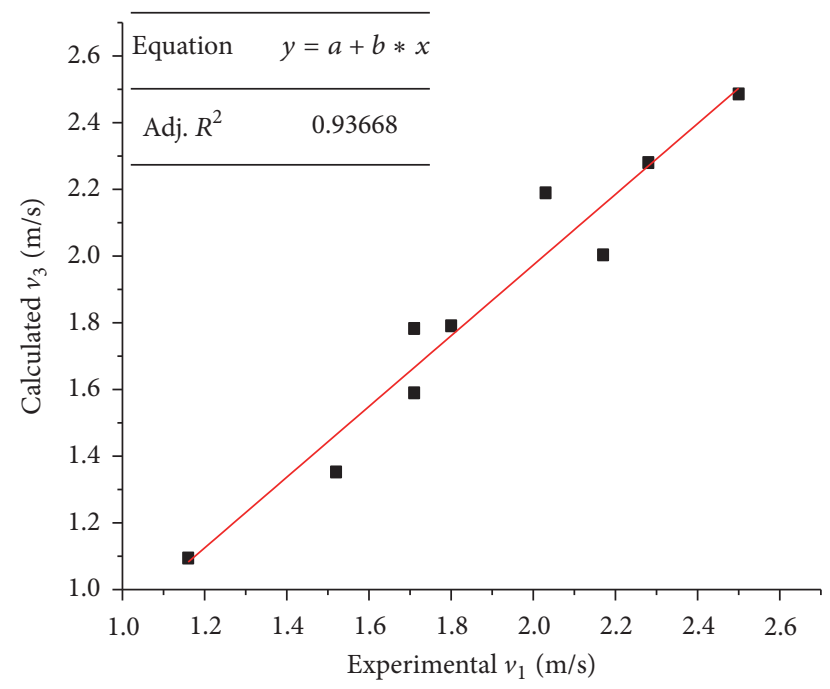

FIgURE 7: A comparison of the calculated values $v_{3}$ and the experimental data $v_{1}$ of the debris flow.

Therefore, we conclude the following: (1) the superelevation climbing ascending slopes using the mean velocity $v_{1}$ for calculation was less than the actual measured maximum superelevation $h_{0}$ with a root-mean-square error (42\%); (2) using (11) to calculate the superelevation climbing ascending slopes resulted in a value close to the actual maximum superelevation $h_{0}$ with a root-mean-square error (16\%), which could potentially meet the actual needs of engineers.

The linear fitting equation is as follows:

$$
\begin{aligned}
& h_{2}=0.9124 h_{0}+0.09, \\
& R^{2}=0.93 .
\end{aligned}
$$

Our experimental results conclusively show that the calculated superelevation climbing ascending slopes based on the Bingham Model is more accurate and reasonable than calculation methods that use the mean velocity of the debris flow. For instance, the confidence limits of our new calculated method were $-21 \% \sim+22 \%$, the root-mean-error was $16 \%$, and the $R$-square was 0.93 . Using (11) to calculate

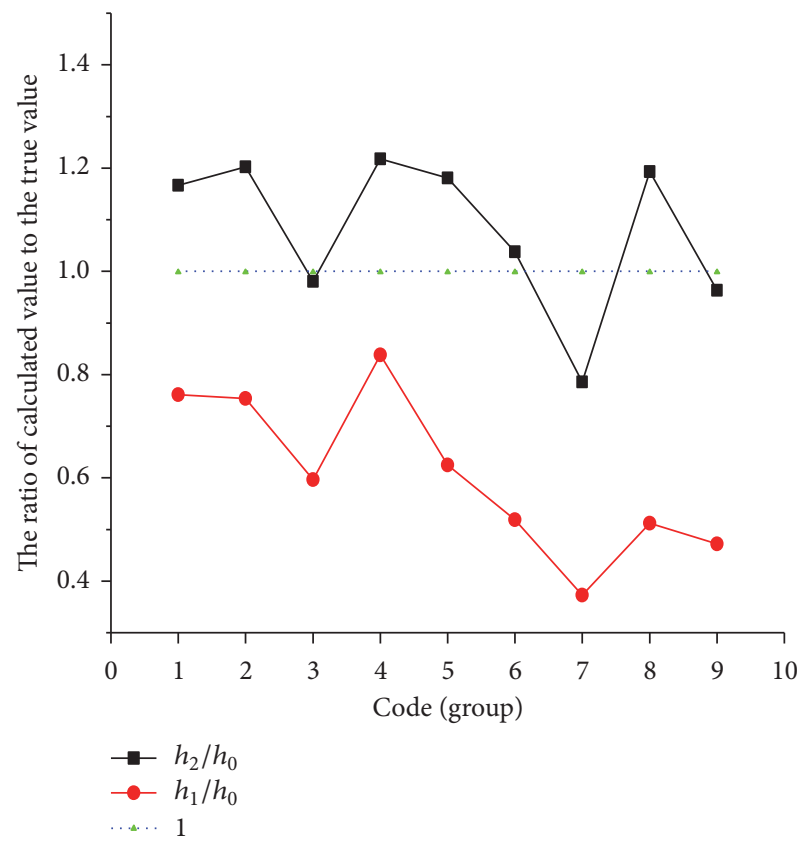

FIGURE 8: Comparison of the superelevation results of the debris flow, where $h_{2} / h_{0}$ represents the ratio of the calculated value using (11) compared to the measured value and $h_{1} / h_{0}$ represents the ratio of the calculated value using (1) compared to the measured value.

the superelevation of the viscous debris flow not only met the limited error range, but also factored in the characteristics of debris flows and the gradient of the gully. We used the hydraulic radius $R$ instead of the mud depth $H$ to calculate the surface velocity and the maximum superelevation in (11) due to a theoretical derivation based on the Bingham Model, which involved the use of a 2-dimensional (2D) model that is more suitable for calculations using the hydraulic radius $R$ rather than the mud depth $H$ (because of the effects of the two inside lateral surfaces of the flume). Apart from this derivation, (9) and (11) are the same. For the indoor experiments, the effects of the two inside lateral surfaces of the flume were obvious, and we calculated the maximum superelevation using (11). While in the field, most of the debris flow's mud depth was much smaller than its width, and 


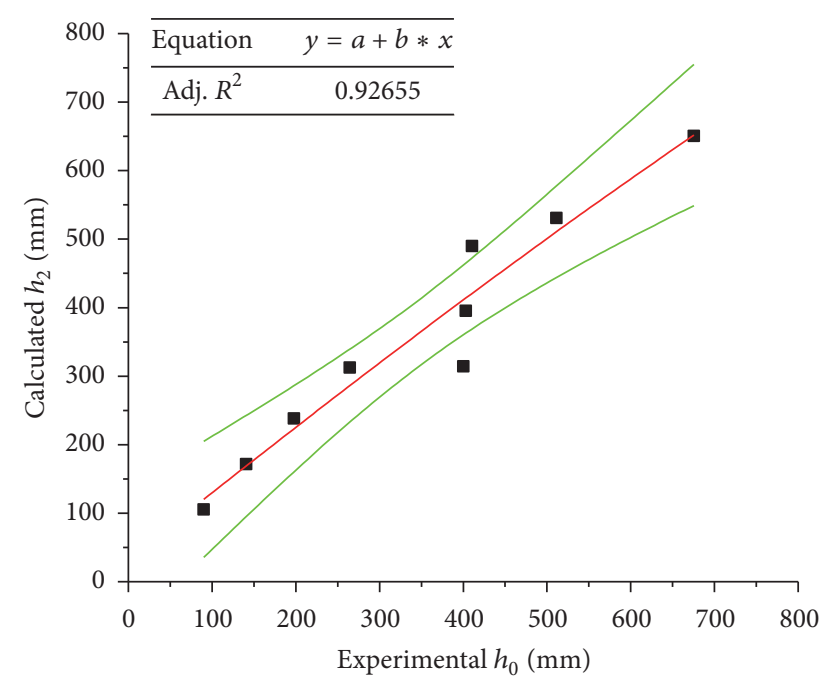

FIgURE 9: A comparison of the calculated values $h_{2}$ and the experimental data $h_{0}$ of the superelevation of the debris flow: linear fit and 95\% confidence limit.

there was little difference between the hydraulic radius $R$ and the mud depth $H$. As such, we used (9) for the real-world application.

\section{Example}

There were less field survey data to validate (9) due to the instantaneous occurrence of debris flow and the absence of rheological parameters. In order to better illustrate this approach, we outline 3 case studies (below) that demonstrate the utility and practical applicability of using (9).

Case 1 is a well-documented debris flow reference case. Zhao et al. [19] investigated an occurrence where the superelevation of debris flow in a bend departed into the superelevation caused by centrifugal movement and superelevation climbing ascending slopes caused by normal velocity. The actual superelevation of the debris flow in the bend was $1.6 \mathrm{~m}$, including the value caused by centrifugal movement $(0.95 \mathrm{~m})$. Therefore, the value caused by normal velocity was $0.65 \mathrm{~m}$. The value using (1) for calculation was $0.4 \mathrm{~m}$, which was less than the theoretical value of superelevation climbing ascending slopes. Using the mean velocity as a standard to design the countermeasure works would pose some risk.

Case 2 is the Yaner debris flow in Gansu Province, China. The Yaner debris flow gully is located in Wu du, Gansu Province, China (E104 $\left.{ }^{\circ} 59^{\prime} 26^{\prime \prime}, \mathrm{N} 33^{\circ} 21^{\prime} 41.43^{\prime \prime}\right)$. The Yaner debris flow gully is a viscous debris flow type gully. The gradient was 0.18 due to the sedimentation of the debris dam between Dam 1 and Dam 2. The density was $20 \mathrm{kN} / \mathrm{m}^{3}$, the mud depth was $0.3 \mathrm{~m}$, the coefficient of viscosity was $24.6 \mathrm{~Pa} \cdot \mathrm{s}$, and the Bingham limit shear stress was $254 \mathrm{~Pa}$ which we collected for field sample. Using (9) for calculation, the superelevation climbing ascending slopes was $0.76 \mathrm{~m}$, while the actual measured superelevation was $0.7 \mathrm{~m}$ with an error of $8 \%$ (the height of wing wall is $1 \mathrm{~m}$ which is used to contrast with the superelevation of debris flow in Figure 10).

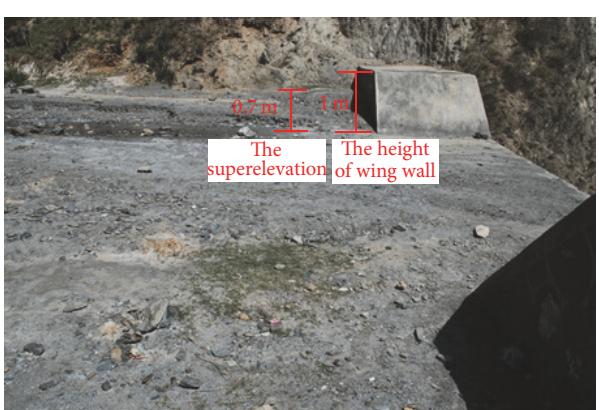

FIGURE 10: The measurement of the superelevation and the wing wall height.
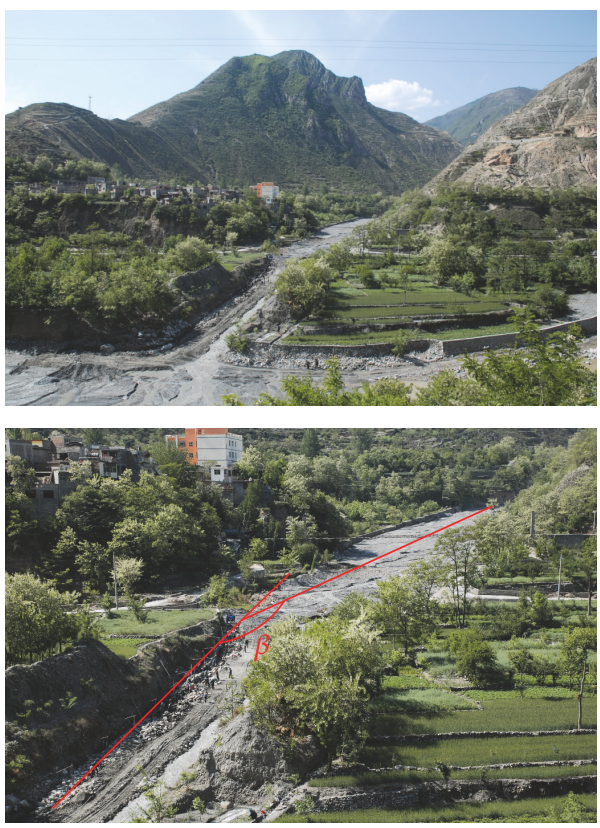

Figure 11: The alluvial fan of the Shimen Gully (before 2015), where $\beta$ in the figure (shown in red) represents the angle between the direction of the debris flow and the surface of the obstacle on the plane parallel to the ground.

Case 3 is the Shimen debris flow in Gansu Province, China $\left(E 104^{\circ} 30^{\prime} 15^{\prime \prime}, \mathrm{N} 33^{\circ} 40^{\prime} 41.48^{\prime \prime}\right)$. Specifically, we used the Shimen Gully, a tributary on the south bank of the Bailong River, as a real-world example. As illustrated by Ning [20], the Shimen Gully is situated in Longnan and is part of the Gansu Province. The area of the catchment was $83 \mathrm{~km}^{2}$ with steep valleys. Through visits and surveys with local people, we determined that Shimen Gully experienced 3 large-scale debris flows that caused enormous economic losses in 1988, 1989, and 1992.

To mitigate debris flow hazards, the local government of the Shimen Gully built diversion dikes (with lengths of 500 meters) perpendicular to the ground $\left(\alpha=0^{\circ}\right)$. The diversion dikes are angled $130^{\circ}$ in the direction of the debris flow on the alluvial fan of the Shimen Gully $\left(\beta=130^{\circ}\right)$; see Figure 11 . Below are relevant measurements and characteristics of the Shimen Gully and the diversion dikes: 
(1) By measuring a large-scale topographic map, we determined that the debris flow gully had an average longitudinal slope $J$ of 0.06 .

(2) According to the actual sample measurements, we determined that the bulk density of the debris flow $\gamma_{c}$ was $21 \mathrm{kN} / \mathrm{m}^{3}$.

(3) The design discharge of the debris flow $Q$ was $60 \mathrm{~m}^{3} / \mathrm{s}$ based on our calculation method.

(4) Based on the rheological experiments on the debris flow and considering the effect of large particles in the field, we determined the debris flow viscous coefficient $\eta$ was $50 \mathrm{~Pa} \cdot \mathrm{s}$. We also determined that the debris flow yield stress $\tau_{B}$ was $245 \mathrm{~Pa}$.

(5) We determined the mud depth $H$ was $1.0 \mathrm{~m}$.

(6) Based on (9),

$$
h=\frac{\gamma_{c}^{2} H^{4} J^{2} \cos ^{2} \alpha \sin ^{2} \beta}{8 \eta^{2} g}\left(1-\frac{\tau_{B}}{\gamma_{c} H J}\right)^{4} .
$$

First, we calculated the maximum superelevation, which was $1.4 \mathrm{~m}$. For extra security we added an additional $0.5 \mathrm{~m}$. The mud depth itself was $1.0 \mathrm{~m}$. These measurements result in a diversion dike with a height of at least $2.9 \mathrm{~m}$. Therefore, in order to ensure the safety of the residents and farmland, all debris flow diversion dikes should have a height of $2.9 \mathrm{~m}$.

\section{Conclusion}

This study used theoretical analytical methods to create a new calculation method for the superelevation of debris flows climbing ascending slopes. We used an indoor flume experiment to verify the accuracy and reasonability of our new equation. We drew the following conclusions from the results of the study.

(1) Our new calculation method for the superelevation of debris flows climbing ascending slopes (based on the Bingham Model) considers the characteristics of debris flows and gullies, which gives it a fundamental advantage over the old equations which only consider the mean velocity.

(2) The results of the indoor flume experiments proved that our new calculation method was accurate and reasonable. With a root-mean-square error (16\%), our calculation method can be used for the actual calculation of the superelevation of debris flow. Our calculation method also provides exact parameters for debris flow protection engineering.

(3) Our calculation method used the Bingham Model, which is appropriate for the calculation of viscous debris flow but inadequate for other diluted debris flows. Further methods and calculations will need to be developed to address this issue.

Ultimately, our new calculation method is able to provide more practical and reliable calculation parameters for debris flow engineering. Moreover, our calculation method can greatly improve preventive engineering efforts, resulting in improved safety and less loss of life and farmland.

\section{Conflicts of Interest}

The authors declare that they have no conflicts of interest.

\section{Acknowledgments}

This study was financially supported by the National Science and Technology Support Program (2014BAL05B01), the STS Project of the Chinese Academy of Sciences (KFJ-EWSTS-094), and the subprogram of the science and technology research and development plan from China Railway (2014G004-A-5). The authors are grateful to Chen Shunli for help during the experiment process.

\section{References}

[1] J. S. Wu, L. Q. Tian, Z. C. Kang et al., Debris Flow and Its Comprehensive Control, Science Press, Beijing, China, 1991 (Chinese).

[2] O. Hungr, S. G. Evans, M. J. Bovis, and J. N. Hutchinson, "A review of the classification of landslides of the flow type," Environmental \& Engineering Geoscience, vol. 7, no. 3, pp. 221238, 2001.

[3] N. S. Chen, Y. C. Cao, and D. F. Li, "Conflux process analysis of disastrous debris flow in the Qiongshan Racine Gully, Danba County, Sichuan Province," Journal of Natural Disasters, vol. 13, no. 3, pp. 104-108, 2004 (Chinese).

[4] O. Hungr, G. C. Morgan, and R. Kellerhals, "Quantitative analysis of debris torrent hazards for design of remedial measures," Canadian Geotechnical Journal, vol. 21, no. 4, pp. 663-677, 1984.

[5] O. Hungr and D. H. McClung, "An equation for calculating snow avalanche runup against barriers," in Proceedings of the Davos Symposium of Avalanche Formation, Movement, and Effects, vol. 162, pp. 605-612, IAHS Publication, 1987.

[6] T. Mizuyama and S. Uehara, "Debris flow in steep slope channel curves," Japanese Journal of Civil Engineering, vol. 23, pp. 243248, 1981.

[7] R. M. Iverson, R. G. LaHusen, J. J. Major, and C. L. Zimmerman, "Debris flow against obstacles and bends: dynamics and deposits," EOS, Transactions of the American Geophysical Union, vol. 75 , no. 44, p. 274, 1994.

[8] M. H. Bulmer, O. S. Barnouin-Jha, M. N. Peitersen, and M. Bourke, "An empirical approach to studying debris flows: implications for planetary modeling studies," Journal of Geophysical Research: Atmospheres, vol. 107, no. 5, pp. 9-1-9-14, 2002.

[9] R. W. Jibson, E. L. Harp, W. Schulz, and D. K. Keefer, "Large rock avalanches triggered by the M 7.9 Denali Fault, Alaska, earthquake of 3 November 2002," Engineering Geology, vol. 83, no. 1-3, pp. 144-160, 2006.

[10] D. Mancarella and O. Hungr, "Analysis of run-up of granular avalanches against steep, adverse slopes and protective barriers," Canadian Geotechnical Journal, vol. 47, no. 8, pp. 827-841, 2010.

[11] E. Choic, W. W. Ngc, P. H. Lawr, D. Song, H. S. Kwanj, and K. S. Hok, "Computational investigation of baffle configuration on impedance of channelized debris flow," Canadian Geotechnical Journal, vol. 52, no. 2, pp. 182-197, 2015.

[12] R. M. Iverson, D. L. George, and M. Logan, "Debris flow run up on vertical barriers and adverse slopes," Journal of Geophysical Research Earth Surface, vol. 121, no. 12, pp. 2333-2357, 2016.

[13] T. Takahashi, "Mechanical characteristics of debris flow," Journal of the Hydraulics Division, vol. 104, no. 8, pp. 1153-1169, 1978. 
[14] T. Takahashi, "Debris flow on prismatic open channel," Journal of the Hydraulics Division, vol. 106, no. 3, pp. 381-396, 1980.

[15] R. M. Iverson, "The physics of debris flows," Reviews of Geophysics, vol. 35, no. 3, pp. 245-296, 1997.

[16] M. Drago, "A coupled debris flow-turbidity current model," Ocean Engineering, vol. 29, no. 14, pp. 1769-1780, 2002.

[17] I. M. Krieger and T. J. Dougherty, "A mechanism for nonnewtonian flow in suspensions of rigid spheres," Transactions of The Society of Rheology (1957-1977), vol. 3, no. 1, pp. 137-152, 1959.

[18] M. Mooney, "The viscosity of a concentrated suspension of spherical particles," Journal of Colloid Science, vol. 6, no. 2, pp. 162-170, 1951.

[19] J. H. Zhao, K. H. Hu, J. B. Tang et al., "A modified debrisflow super-elevation formula with the run-up effect," Journal of Hydraulic Engineering, vol. 46, no. 2, pp. 190-196, 2015 (Chinese).

[20] N. Ning, Study on Hazards Assessment of Debris Flow in the Bailong River Basin for Different Scales, Lanzhou University, Lanzhou, China, 2014 (Chinese). 


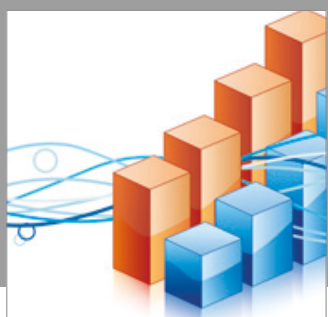

Advances in

Operations Research

vatersals

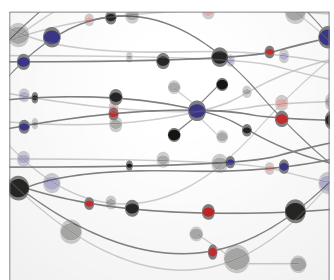

\section{The Scientific} World Journal
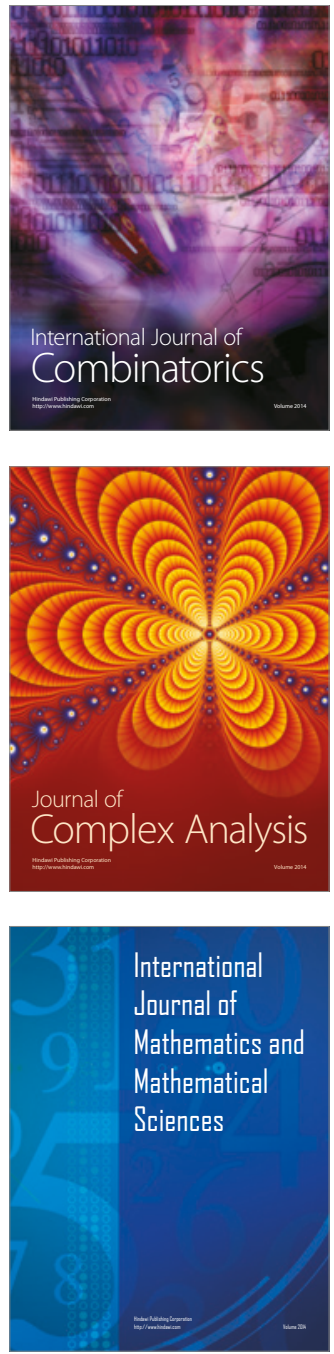
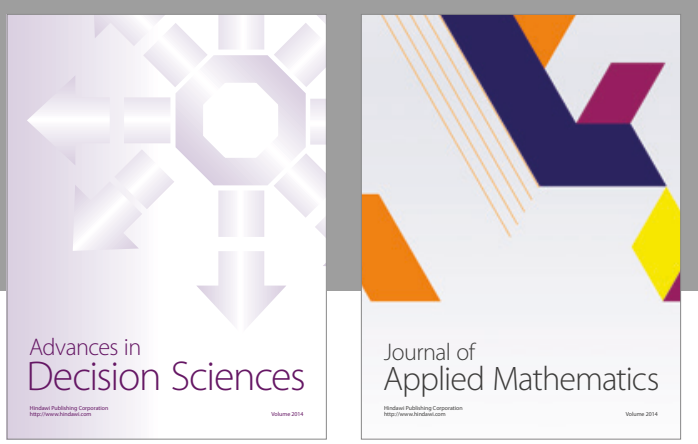

Algebra

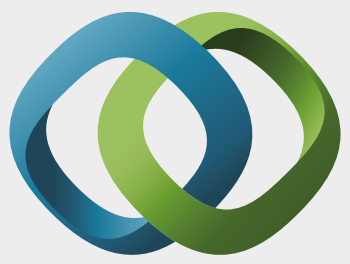

\section{Hindawi}

Submit your manuscripts at

https://www.hindawi.com
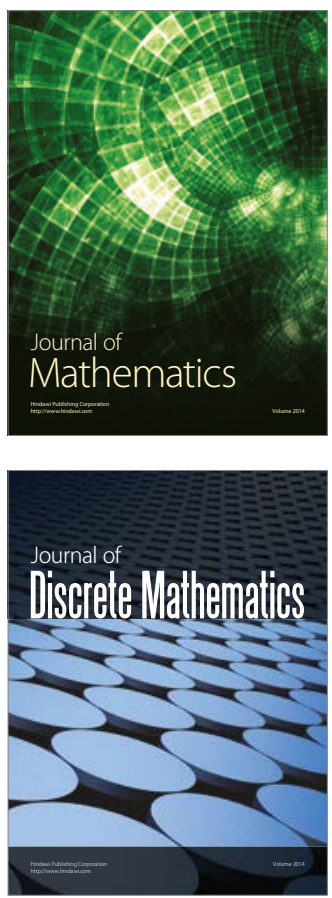

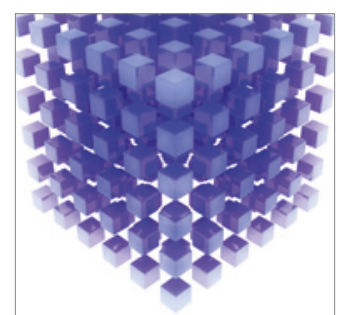

Mathematical Problems in Engineering
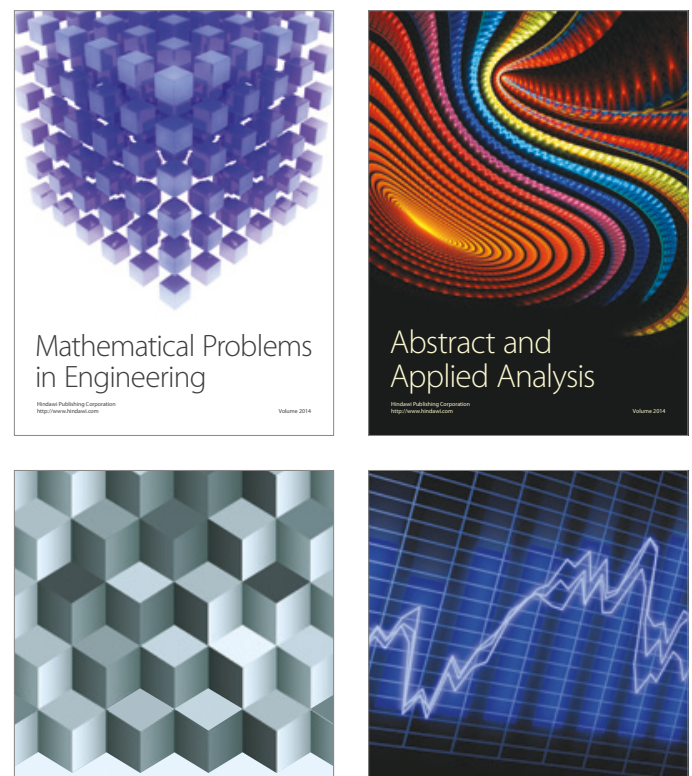

Journal of

Function Spaces

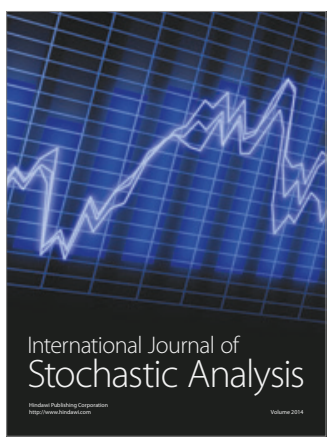

Probability and Statistics
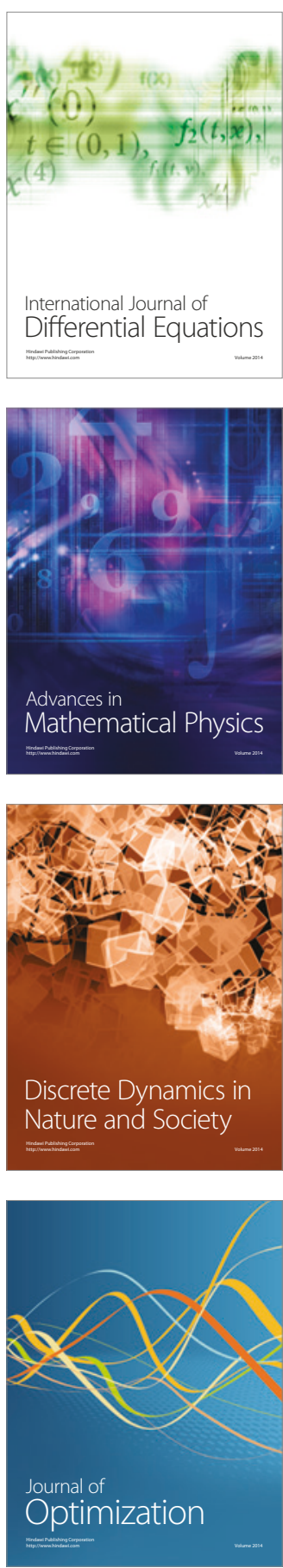